\title{
Türk Sermaye Piyasasında Fiyat ve İşlem Hacmi îlişkisi: Zamanla Değişen Asimetrik Nedensellik Analizi
}

\author{
Price and Trade Volume Relationship in Turkish Stock Market: A Time-Varying \\ Asymmetric Causality Analysis
}

Veli YILANCI' ${ }^{1}$, Şeref BOZOKLU²

\begin{abstract}
ÖZET
Bu çalışma, Türk sermaye piyasasında hisse senedi fiyatları ile işlem hacmi arasındaki nedensellik ilişkisini günlük veriler aracılığıyla 1990-2012 dönemi için araştırmaktadır. Literatürdeki önceki çalışmalardan farklı olarak, pozitif ve negatif şoklara verilen tepkilerin farklı olabileceği ve aynı zamanda elde edilen sonuçların zamana bağlı olarak değişebileceği dikkate alınarak, zamanla değişen asimetrik nedensellik testi kullanılmıştır. Sonuçlar, işlem hacminin bileşenlerinden hisse senedi fiyatlarının bileşenlerine doğru tek yönlü bir nedensellik ilişkisi olduğunu ve bu ilişkinin zamana bağlı olarak değiştiğini göstermektedir.
\end{abstract}

Anahtar Kelimeler: Türk sermaye piyasası, zamanla değişen asimetrik nedensellik testi, fiyat-hacim ilişsisi.

\section{GíRiş}

Ekonomilerin büyük ölçüde küreselleşmesi, finansal piyasalarda görülen serbestleşme eğilimleri ve bilgi teknolojilerinde yaşanan ilerlemeler, finansal piyasalar hakkında yapılan çalışmaların gözle görülür biçimde artmasına neden olmuştur. Bu bağlamda finansal ekonomi literatürünün önemli araştırma alanlarından birini yatırımcıların firmalara yönelik beklentilerini yansıtan hisse senedi fiyatlarındaki değişimin analizi oluşturmaktadır. Hisse senedi fiyatlarındaki hareketin temel nedenlerinden biri, yeni bilginin piyasaya ulaşması sonucunda yatırımcıların beklentilerinde meydana gelen değişimdir. Bununla birlikte, yatırımcıların özdeş olmaması nedeniyle yeni haberlere aynı şekilde tepki vermemeleri ya da yatırımcılar özdeş olsalar bile başlangıçtaki beklentilerinin farklı olması nedeniyle piyasada yeni bir bilginin ortaya çıkışı hisse senedi fiyatlarının her zaman değişeceği anlamına da gelmemektedir: ilk durumda, bir firmanın kar payı ödemesinde artışa gideceğini açıklaması, yatırımcıların bir bölümünün bu yeni bilgiyi firmanın gelecek dönemdeki performansının olumlu olacağına yorarak, hisse senedine olan taleplerinin artmasına ve dolayısıyla hisse senedi fiyatlarının yükselmesi-

\begin{abstract}
This paper examines the relationship between stock prices and trade volume for the 1990-2012 period by using daily data in Turkish stock market. Contrary to the previous studies in the literature, considering that reactions to the positive and negative shocks may be different from each other, and also the test results may change over time, we employ a time varying asymmetric causality test. The results reveal that there is only a unidirectional causality from the components of trade volume to the components of stock prices and this relationship changes over time.
\end{abstract}

Keywords: Turkish stock market, time-varying asymmetric causality test, price-volume relationship.

ne neden olur. Öte yandan sadece sermaye kazancını dikkate alan yatırımcılar ise bu yeni bilgi karşısında portföylerindeki hisse senetlerini satar ve bu durum da hisse senedi fiyatlarının düşmesine sebep olur; ikinci durumda ise yatırımcılar başlangıçta asimetrik beklentilere sahip olduklarında, aynı bilgiyi edinmelerine rağmen sermaye piyasalarında uygulayacakları işlemler aynı olmamaktadır. Sonuçta, her iki durumda da hisse senedi fiyatları piyasadaki tüm bilgiyi yansıtmamaktadır.

Fama (1970) hisse senetlerinin cari fiyatlarının geçmiş döneme dair tüm bilgiyi yansıtması durumunda piyasa etkinliğinin zayıf olacağını belirtmiştir. Piyasa etkin olduğunda menkul kıymetlerin geçmiş dönem fiyatları gelecek dönem fiyat değişikliklerinin tahmininde kullanılamayacak, dolayısıyla teknik analiz araçları gereksiz olacaktır. Bununla birlikte, teknik analizi savunanlar, geçmiş dönem menkul kıymet fiyatlarındaki bilginin cari dönem fiyatlarına tam yansımadığını ileri sürmekte, dolayısıyla geçmiş dönemdeki fiyatların gözlenerek gelecek dönem fiyatları hakkında bilgi edinilebileceğini ifade etmektedirler. Teknik analizin faydalı bir araç olduğunu ileri sürenler işlem hacminin fiyatlarda değişime yol açtı̆̆ı 
argümanının geçerliliğini savunmaktadırlar (Blume vd.,1994:153). Bu bağlamda Blume vd. (1994) işlem hacminin fiyatlara yansıyan bilginin kalitesi hakkında iyi bir gösterge olabileceğini belirtmiş ve teknik analistlerce hisse senedi getirilerinin tahmin edilmesinde işlem hacminin kullanımına ilişkin teorik bir temel oluşturmuştur.

Fiyatlar, piyasanın mikro yapısı, likidite ve riskten korunma (hedging) gibi faktörler sebebiyle denge patikasından sapmalar gösterebilir. Fiyatlama hataları ise gürültülü işlem (noisy trade) ve yeni bilgiye verilen hatalı tepkiden kaynaklanabilir. Dolayısıyla, işlem hacminin davranışını ve hisse senedi getirisi ile olan ilişkisini kavramak, yatırımcılara hisse senedi piyasasının gelecekte alacağı şekli anlama konusunda yararlı olacaktır. Ayrıca fiyat-hacim ilişkisi piyasanın etkinliği için işlem stratejisi olarak ve teknik analizin faydalarını değerlendirmek için de kullanılabilir. Karpoff (1987:109) fiyat-hacim ilişkisinin önemine ilişkin dört gerekçe sunmuştur. İlk olarak, fiyat-hacim ilişkisi piyasaya gelen bilgi oranına, piyasa fiyatlarının yeni bilgiyi ne derecede yansıttığına, piyasanın büyüklüğüne ve kısa vadeli satış kısıtlarının varlığı gibi finansal piyasaların yapısına yönelik değerlendirmelerin yapılabilmesine imkân tanımaktadır. İkinci olarak, fiyat-hacim ilişkisinin durumunun bu değişkenlere ilişkin gözlemlerin bileşiminden hareketle vaka analizlerinde kullanılabilmektedir. Fiyat değişiklikleri ve işlem hacmi bir arada oluşuyorsa iki değişken arasındaki ilişkiyi içeren testlerin gücü artacaktır. İlgili testlerin oluşturulması ve bu testlere dayanan çıkarsamaların oluşturulması, işlem hacmi ile fiyat değişikliğinin ortak dağılımına bağlı olacaktır. Bu durum özellikle, fiyat değişikliklerinin nedeninin yeni bilginin piyasa tarafından fark edilmesi olduğu düşünüldüğünde ve bu değişimlere karşılık gelen hacim değişiminin yatırımcıların yeni bilginin anlamına ilişkin aynı fikirde olmadığı biçiminde yorumlandığında önemli olmaktadır. Üçüncü olarak, fiyat-hacim ilişkisi spekülâtif fiyatların ampirik dağılımına ilişkin tartışmaların önemli bir konusudur. Bu bağlamda, vaka incelemelerinde fiyat-hacim ilişkisinin, vakanın henüz gerçekleşmediği zaman diliminden vakanın geçerli olduğu zamana dek fiyat sürecinin varyansındaki değişimleri ölçmek amacıyla kullanılması mümkündür. Dördüncü olarak, fiyat-hacim ilişkisi gelecek piyasaları için gelecek sözleşmesinin teslimine kalan süre, işlem hacmini ve dolayısıyla fiyat değişkenliğini etkilemesi açısından önemli çıkarsamalar içermektedir.

Hisse senedi getirisi ile işlem hacmi arasındaki eş anlı ilişkiyi analiz eden ilk çalışmalar genel olarak iki değişken arasında güçlü bir pozitif ilişki olduğuna dikkati çekmektedir (Karpoff (1987)'. Bu çalışmaları izleyen araştırmalar ise zaman serisi analizi tekniklerini kullanarak iki değişken arasındaki nedensellik ilişkisini araştırmışlardır. Çalışmamızı, literatürdeki önceki çalışmalardan ayıran temel fark, pozitif ve negatif şokların etkisinin aynı olmayabileceğini dikkate alarak asimetrik nedensellik testini zamanla değişen formda kullanmaktır. Bu yöntem aracılığıyla Borsa İstanbul'daki fiyat-hacim ilişkisinin incelendiği çalışmanın 2. bölümünde fiyat-hacim ilişkisine yönelik teorik ve uygulamalı literatür özetlenmektedir. 3. bölümde ekonometrik yöntem tanıtılmakta ve 4 . bölüm ise uygulama bölümünü içermektedir. Çalışma, analizin sonuçlarının değerlendirildiği 5. bölüm ile tamamlanmaktadır.

\section{SEÇILMIŞ LITERATÜR}

Hisse senedi fiyatları ile işlem hacmi arasında gerek eş anlı, gerekse de gecikmeli ilişkiyi analiz eden alternatif teorik modeller geliştirilmiştir²:

- Dağılımların Karması (mixture of distribution) modeli Clark (1973) ile Epps ve Epps (1976) tarafından geliştirilmiştir. Tüm piyasa katılımcılarının fiyatlarda değişime yol açan yeni bilgi akışlarını eş anlı olarak algıladığının varsayıldığı bu modelde, fiyat değişikliği ve işlem hacminin ortak bir faaliyete dayanmaları nedeniyle pozitif eş anlı bir ilişki içinde oldukları ifade edilmekte ve bu pozitif ilişki için alternatif açıklamalar getirilmektedir. Clark (1973) bilgi akışına, işlem hacmini etkileyen bir gölge değişken olarak yaklaşmış ve işlem hacminin ortak gölge faktör ve bilginin hızı için bir gösterge kabul edilmesinin, fiyat değişimlerinin varyansı ile hacim arasındaki eş anlı ilişkinin pozitif oluşunu açıkladığını belirtmiştir. Ayrıca işlem hacmi ile hisse senedi fiyatları arasında herhangi bir nedensellik ilişkisinin bulunmadığını da ifade etmiştir. Epps ve Epps (1976), yeni bilginin piyasaya ulaşmasına bağlı olarak rezervasyon fiyatlarının yatırımcılar tarafından gözden geçirilmesi nedeniyle işlem hacmini piyasadaki taraflar arasındaki uyumsuzluğu değerlendirmek amacıyla bir gösterge olarak kullanmıştır. Bu bağlamda, yatırımcılar arasındaki uyumsuzluk arttıkça işlem hacmi de artacaktır. Sonuç olarak Epps ve Epps (1976) işlem hacminden hisse senedi getirilerinin mutlak değerine doğru pozitif bir ilişki olduğunu belirtmiştir.

- Ardışık Bilgi Akışı (sequantial information arrival) modeli Copeland (1976) tarafından ileri sürülmüş ve Jennings v.d. (1981) tarafından geliştirilmiştir. Bilginin piyasaya ulaşması ve yarattığı etkileri analiz eden bu model, asimetrik bilgi yaklaşımına dayanmakta ve piyasaya ulaşan yeni bilginin yatırımcılar tarafından eş anlı olarak algılanmadığını, tersine yeni bilginin algılanma sürecinin ardışık bir süreç takip ettiğini ifa- 
de etmektedir. Ardışık Bilgi modeli, bilgiyi edinmede yaşanan gecikmeler nedeniyle piyasada geçici dengelerin oluşabileceğini ve sadece tüm katılımcıların yeni bilgiyi edindikleri durumda nihai piyasa dengesinin kurulacağını ifade etmektedir. Dolayısıyla, ardışık bilgi akışı nedeniyle gecikmeli işlem hacmi, cari dönemdeki mutlak getiriler için bilgi sağladığı gibi gecikmeli mutlak getiriler de cari işlem hacmi hakkında bilgi içermektedir. Model, fiyat değişiminin mutlak değeri, diğer bir ifadeyle fiyat değişkenliği ile işlem hacmi arasında pozitif eş anlı ilişki olduğunu ve aynı zamanda iki değişken arasında çift yönlü nedensellik ilişkisinin olduğunu ileri sürmektedir.

İki model arasındaki temel fark; yeni bir bilginin ortaya çıkması sonucu piyasanın yeni dengeye uyarlanma hızında yatmaktadır. Dağılımların Karması modelinde yeni dengeye hızlıca ulaşılırken, Ardışık Bilgi Akışı modelinde nihai dengeye hızla ulaşılmayacağı düşünülmektedir. Her iki yaklaşımda da iki değişken arasında pozitif bir eş anlı ilişki söz konusudur. Ardışık Bilgi Akışı modeli işlem hacminin, geçmiş dönem değerlerinin cari dönem fiyatlarını ve geçmiş dönem fiyatlarının, cari işlem hacmini açıklayacak bilgi içerdiği için, iki değişken arasında pozitif nedensellik ilişkisini de öngörmektedir. Her iki yaklaşım da değişkenlerin pozitif ve negatif değişimleri arasında simetri olduğunu kabul etmektedir.

- Lakonishok ve Smidth (1989) vergileme ve vergileme dışındaki nedenler dolayısıyla cari işlem hacminin, geçmiş fiyat hareketleri ile ilişkili olabileceğini belirtmektedir. Vergi ile ilişkili nedenler, takvim yılı boyunca karşılaşılan sermaye kazançları ve kayıplarının optimal zamanlaması ile ilişkilidir. Vergi dışı nedenler ise bilanço düzenlemeleri, portföy değişiklikleri ve farklı stratejiler gibi gerekçeleri içermektedir. Dolayısıyla, piyasada gerçekleşen işlem, vergileme nedeniyle gerçekleşmişse nedensellik ilişkisi negatif, vergileme dışındaki herhangi bir nedenden gerçekleşmişse nedensellik ilişkinin pozitif olması beklenmektedir.

- Gürültülü İşlemciler (noise traders) modeline göre finansal piyasalarda, gürültülü işlemcilerin faaliyetleri iktisadi temellere dayanmadığı için, bu işlemciler hisse senedi fiyatlarının kısa dönemde denge değerinden sapmasına yol açan geçici bir bileşen içermesine neden olmaktadır. Uzun dönemde ise bu geçici bileşen kaybolmakta ve hisse senedi getirileri ortalamasına dönme eğilime girmektedir. Ayrıca bu model hisse senedi getirilerinin kısa dönemde pozitif otokorelasyon gösterdiğini, uzun dönemde ise otokorelasyonun negatife döndüğünü belirtmektedir. Gürültülü işlemcilerin fiyatlarda dalgalanmaya yol açan stratejiler izlemeleri işlem hacminden getirilere doğru pozitif bir nedensellik ilişkisinin oluşmasına neden olmaktadır. Ayrıca, alınan kararların geçmiş fiyat hareketlerine bağlı olması nedeniyle gürültülü işlemciler, pozitif geri besleme içeren işlemler yapmakta ve bunun sonucunda da hisse getirilerinden işlem hacmine doğru pozitif bir nedensellik söz konusu olmaktadır (DeLong vd.,1990). Sonuç olarak iki değiş̧ken arasında iki yönlü pozitif nedensellik söz konusudur.

İşlem hacmi ve hisse senedi getirisi arasındaki ilişkiyi araştıran ilk çalışmalar işlem hacmi ile getiri veya getirinin mutlak değeri ya da karesi (değişkenlik, volatilite) arasındaki eş anlı ilişkiyi analiz ederken (Jennings, vd., 1981; Tauchen ve Pitts, 1983; Karpoff, 1987), yakın dönemdeki çalışmalar ise zaman serisi analizi tekniklerini kullanarak, fiyat değişiminin varyansı (karesi) ile işlem hacmi arasındaki ilişkiyi (Andersen, 1996; Lee ve Rui, 2000) ve fiyat değişimi ile işlem hacmi arasındaki ilişkiyi (Campbell, vd., 1993; Chen, vd., 2001; Lee ve Rui, 2002; Chuang, vd., 2009) araştırmaktadır. Bu çalışmaların büyük bir kısmında örneklem, gelişmiş ülkeleri içermektedir. Gelişmekte olan ülkeler için iki değişken arasındaki ilişkiyi analiz eden çalışmalar (Silvapulle ve Choi, 1999; Assogbavi ve Osagie, 2006; Pisedtasalasai ve Gunasekarage, 2007) bilgi akışının gelişmiş ülkeler ile benzer olmadığını ve piyasalar arasında belirgin kurumsal farklılıklar olduğunu göstermektedir. Bu çalışmaların çoğunluğunun değişkenler arasındaki olası asimetrik ve doğrusal olmayan ilişkileri dikkate almadığı dikkati çekmektedir. Asimetrik ve doğrusal olmayan ilişkiler heterojen beklentiler ve açığa satış maliyetleri nedeniyle ortaya çıkmaktadır (Assogbavi, vd., 1995). Bu tür ilişkileri dikkate alan çalışmaların literatürde yakın zamanda ilgi odağı olduğu da belirtilmelidir (Chuang, vd., 2009; Lin, 2013; Ngo ve Surendranath, 2008; Al-Deehani, 2007; Gerlach, vd., 2006; Hiemstra ve Jones, 1994). Türkiye için yapılan çalışmalarda, gerek toplulaştırılmış hisse senedi fiyatı ile işlem hacmi ilişkisinin (Kamath, 2007; Gündüz ve Hatemi, 2005; Gökçe, 2002; Umutlu, 2008; Çukur, vd.,2012), gerekse de belirli bir sektöre veya endekse ait şirketlerin hisse senedi fiyatları ile işlem hacmi ilişkisinin (Elmas ve Timurlenk, 2009; Bayrakdaroğlu ve Nazlıoğlu, 2009; Yörük vd., 2006; Kayalıdere ve Aktaş, 2009; Başşı, vd.,1996) analiz edildiği gözlenmektedir.

Genel olarak ampirik araştırmaların ortak bir sonuca varamadıkları, incelenen dönem ve kullanılan ekonometrik tekniğe göre elde edilen sonuçların farklılaştığı görülmektedir ${ }^{3}$.

\section{EKONOMETRIK YÖNTEM}

Geleneksel Granger (1969) nedensellik testinde, bir değişkenin geleceğe yönelik tahmininde ikinci bir değişkenin faydalı bilgi sağlayıp sağlamadığı sınanır. 
Literatürde, nedensellik analizi için çeşitli testler geliştirilmiştir (Sims, 1972; Hsiao, 1981; Toda ve Yamamoto, 1995; Hacker ve Hatemi, 2006). Bu testler pozitif şokların etkisiyle negatif şokların etkisini aynı kabul etmektedir. Fakat finansal piyasalarda, asimetrik bilginin varlığı ve piyasa katılımcılarının heterojen olması durumunda, katılımcıların aynı büyüklükteki pozitif ve negatif şoklara benzer tepkileri vermemesi nedeniyle bahsi geçen testlerden elde edilen sonuçların yanıltıcı olabileceği ifade edilebilir.

Pozitif ve negatif şoklar arasındaki ilişkinin, değişkenler arasındaki ilişkiden farklı olabileceğini ilk kez Granger ve Yoon (2002) ileri sürmüştür. Granger ve Yoon (2002) iktisadi serilerin şoklara birlikte tepki verdiklerinde eşbütünleşik olduklarını, ayrı ayrı tepki verdiklerinde ise aralarında bir eşbütünleşme ilişkisi olamayacağını ifade ettikten sonra, serilerin belirli bir türdeki şoka birlikte karşılık verebileceklerini belirterek, veriyi birikimli pozitif ve negatif değişmelerine ayrıştırıp, bu parçalar arasındaki uzun dönemli ilişkiyi incelemişlerdir. Hatemi-J (2012) ise Granger ve Yoon (2002) yaklaşımını nedensellik analizi için geliştirmiştir. Bu asimetrik nedensellik testinde, Granger ve Yoon (2002) eşbütünleşme analizinde olduğu gibi serilerin dinamiğini anlamaya yardımcı olacak ve muhtemel geleceğe yönelik tahminleri geliştirmeye imkân verecek saklı yapıyı bulmak amaçlanmaktadır.

$t=1,2, \ldots, T$ iken $y_{1,0}$ ve $y_{2,0}$ başlangıç değerlerini göstermek üzere, aşağıdaki gibi bileşenlerine ayrılabilen $y_{1 t}$ ve $y_{2 t}$ gibi iki bütünleşik seri arasındaki nedensellik analizinin test edildiğini varsayılsın ${ }^{4}$ :

$$
\begin{aligned}
& y_{1 t}=y_{1 t-1}+\varepsilon_{1 t}=y_{1,0}+\sum_{i=1}^{t} \varepsilon_{1 i} \\
& y_{2 t}=y_{2 t-1}+\varepsilon_{2 t}=y_{2,0}+\sum_{i=1}^{t} \varepsilon_{2 i}
\end{aligned}
$$

Pozitif ve negatif şoklar denklem (3)'deki gibi gösterilirse:

$$
\begin{aligned}
& \varepsilon_{1 i}^{+}=\operatorname{maks}\left(\varepsilon_{1 i}, 0\right), \quad \varepsilon_{1 i}^{-}=\min \left(\varepsilon_{1 i}, 0\right), \\
& \varepsilon_{2 i}^{+}=\operatorname{maks}\left(\varepsilon_{2 i}, 0\right), \quad \varepsilon_{2 i}^{-}=\min \left(\varepsilon_{2 i}, 0\right)
\end{aligned}
$$

$\varepsilon_{1 i}=\varepsilon_{1 i}^{+}+\varepsilon_{1 i}^{-}$ve $\varepsilon_{2 i}=\varepsilon_{2 i}^{+}+\varepsilon_{2 i}^{-}$şeklinde ifade edilebilir. Bu bilgi ışığı altında (1) ve (2) numaralı eşitlikleri düzenleyerek denklem (4)'deki gibi yeniden yazmak mümkündür:

$$
\begin{aligned}
& y_{1 t}=y_{1 t-1}+\varepsilon_{1 t}=y_{1,0}+\sum_{i=1}^{t} \varepsilon_{1 i}^{+}+\sum_{i=1}^{t} \varepsilon_{1 i}^{-} \\
& y_{2 t}=y_{2 t-1}+\varepsilon_{2 t}=y_{2,0}+\sum_{i=1}^{t} \varepsilon_{2 i}^{+}+\sum_{i=1}^{t} \varepsilon_{2 i}^{-}
\end{aligned}
$$

Her değişkende yer alan pozitif ve negatif şoklar ise birikimli formda denklem (5)'de ifade edilmektedir:

$$
y_{1 i}^{+}=\sum_{i=1}^{t} \varepsilon_{1 i}^{+}, \quad y_{1 i}^{-}=\sum_{i=1}^{t} \varepsilon_{1 i}^{-}, \quad y_{2 i}^{+}=\sum_{i=1}^{t} \varepsilon_{2 i}^{+}, \quad y_{2 i}^{-}=\sum_{i=1}^{t} \varepsilon_{2 i}^{-}
$$

Hatemi-J (2012) testinde, $y_{t}^{+}$değişkeninin $\left(y_{1 t}^{+}, y_{2 t}^{+}\right)$ikilisine eşit olduğu varsayılarak, bu bileşenler arasındaki nedensellik ilişkisi aşağıdaki $p$ gecikmeli vektör otoregresif modeli (VAR) kullanarak test edilir ${ }^{5}$ :

$$
y_{t}^{+}=\alpha+A_{1} y_{t-1}^{+}+\ldots+A_{p} y_{p-1}^{+}+u_{t}^{+}(6)
$$

Denklem (6) 'da, $y_{t}^{+}, 2 \times 1$ boyutunda değişken vektörü, $\alpha$ ve $u_{t}^{+}$ise sırasıyla $2 \times 1$ boyutunda sabit değişken ve hata terimi vektörlerini göstermektedir.

$A_{r}$ ise $2 \times 2$ boyutunda $r$ mertebesinde, gecikme uzunluğu bilgi kriterleri kullanılarak belirlenen parametre matrisidir.

Seriler arasında Granger-nedenselliğin olmadığını gösteren temel hipotezi test etmek için kullanılacak Wald istatistiğini elde edebilmek amacıyla denklem (6)'te gösterilen VAR modeli denklem (7)'deki gibi tanımlanabilir:

$$
Y=D Z+\delta
$$

Denklem (7)'de yer alan terimlerin açık biçimleri denklem (8)'deki gibi ifade edilebilir:

$$
\begin{aligned}
Y & :=\left(y_{1}^{+}, y_{2}^{+}, y_{3}^{+}, \ldots, y_{T}^{+}\right) \\
D & :=\left(\alpha, A_{1}, A_{2}, A_{3}, \ldots, A_{p}\right) \\
Z & :=\left(Z_{0}, Z_{1}, Z_{2}, \ldots, Z_{T-1}\right) \\
Z_{t} & :=\left[\begin{array}{l}
1 \\
y_{t}^{+} \\
y_{t-1}^{+} \\
\cdot \\
\cdot \\
y_{t-p+1}^{+}
\end{array}\right] \\
\delta & :=\left(u_{1}^{t}, u_{2}^{t}, u_{3}^{t}, \ldots, u_{T}^{t}\right)
\end{aligned}
$$


$Y ;(n \times T)$ boyutunda, $D ;(n \times(1+n p))$ boyutunda, $Z ;((1+n p) \times T)$ boyutunda $Z_{b}$; $((1+n p) \times 1)$ boyutunda ve nihayet $\delta$ ise $(n \times T)$ boyutunda matrisleri göstermektedir. Granger nedenselliğin olmadığını gösteren temel hipotez ( $\left.H_{0}: C \beta=0\right)$ Wald istatistiğiyle sınanabilir:

$$
W=(C \beta)^{\prime}\left[C\left(\left(Z^{\prime} Z\right)^{-1} \otimes S_{U}\right) C^{\prime}\right]^{-1}(C \beta)
$$

Denklem (9)'da yer alan $\otimes$, Kronecker çarpımını, $C$ kısıtları içeren gösterge fonksiyonunu göstermektedir. Burada $\beta=\operatorname{vec}(D)$ şeklindedir ki, vec sütunyığma operatörünü ifade etmektedir. $q$ her VAR eşitliğinde yer alan gecikme sayısını göstermek üzere, $S_{U},\left(\hat{\delta}_{U}^{\prime} \hat{\delta}_{U}\right) /(T-q)$ şeklinde kısıtsız VAR modeli için hesaplanan varyans-kovaryans matrisini göstermektedir.

Hatemi-J (2012) asimetrik nedensellik analizinde; dört önemli durum göze çarpmaktadır: VAR modelin gecikme uzunluğunun belirlenmesi, modele ilave edilecek ek gecikme uzunluğunun belirlenmesi, Wald test istatistiği için kritik değerlerin elde edilmesi ve zamana bağlı olarak nedensellik ilişkisinin değişmesi.

Lütkepohl (1985) ile Hacker ve Hatemi-J (2008) çalışmalarında VAR modelleri için Bayesyen ve Hannan-Quinn bilgi kriterlerinin, diğer bilgi kriterlerine göre daha iyi sonuçlar verdiğini ispat etmişlerdir. Hatemi-J (2003) ise bu iki bilgi kriterinin birbirinden farklı sonuçlar verebileceği durumlar olabileceğini öne sürerek, bu iki kriteri içeren yeni bir bilgi kriteri geliştirmiştir. Bu çalışmada, Hatemi-J (2003)'nin literatüre kazandırdığı bu yeni bilgi kriteri kullanılarak uygun gecikme uzunluğuna karar verilecektir. Bu kriteri denklem (10)'daki gibi göstermek mümkündür:

$$
\begin{aligned}
& H J C=\ln \left(\operatorname{det} \hat{\Omega}_{j}\right)+j\left(\frac{n^{2} \ln T+2 n^{2} \ln (\ln T)}{2 T}\right) \\
& (j=0,1,2, \ldots, K)
\end{aligned}
$$

Denklem (10)'da yer alan $\hat{\Omega}_{j}$, gecikme uzunluğu $j$ iken varyans-kovaryans matrisinin maksimum benzerlik tahmincisini, $n$ ve $T$ ise sırasıly VAR modelindeki denklem sayısını ve toplam gözlem sayısını göstermektedir.

Granger nedensellik testinde serilerin durağan olmaması durumunda öncelikle aralarındaki eşbütünleşme ilişkisi sınanır, seriler arasında uzun dönemli bir ilişki olması halinde hata düzeltme modeline dayalı nedensellik analizi, bu ilişkinin olmaması halinde ise serilerin bütünleşme seviyesi kadar farkı alınarak dahil edildiği VAR modele dayalı nedensellik testi uygulanır. Serilerin farkının alınması bilgi kaybına, eşbütünleşme ilişkisinin varlığına bakılması ise ön test eğimlerine neden olabilir. Toda ve Yamamoto (1995) bu problemlerin üstesinden gelebilmek için VAR modele, ilgili serilerin maksimum bütünleşme derecesi kadar, Dolado ve Lütkepohl (1996) ise sadece bir tane ilave gecikme eklenmesini önermiştir. Bu çalışmada Dolado ve Lütkopohl (1996)'ın önerisi izlenerek uygun gecikme uzunluğu HJC kriteriyle belirlenmiş olan VAR modele ilave 1 gecikme eklenecektir.

Finansal veriler genellikle normal dağılmamakta ve bu durum kısıt sayısı kadar serbestlik derecesiyle

$\chi^{2}$ dağılan Wald testinin asimptotik dağılımını etkilemektedir. Bu sorunun üstesinden gelmek için ise kritik değerler bootstrap simülasyonlarıly elde edilecektir.

Diğer bir önemli husus; zamana bağlı olarak seriler arasındaki asimetrik Granger nedensellik ilişkisinde meydana gelebilecek değişimlerdir. Nedensellik ilişkisi, global ekonomik ve politik olayların etkisiyle zamanla değiş̧ebilir (Tang, 2008). Zamanla değişen nedensellik analizi kullanılarak nedensellik ilişkisinin bu istikrarlıı̆̆ı test edilebilmektedir ${ }^{6}$. Bu çalışmada Hatemi-J (2012) tarafından geliştirilen asimetrik nedensellik testinin zamanla değişen biçimi literatüre kazandırılarak, zaman boyunca pozitif ve negatif şoklar arasındaki nedensellik ilişkisinin istikrarlılığı sınanacaktır.

Zamanla değişen asimetrik nedensellik analizi için öncelikle analizin uygulanacağı alt örnek boyutuna karar vermek gerekmektedir. Brooks ve Hinich (1998)'de belirtildiği gibi testin uygulanacağı gözlem boyutu testi geçerli bir şekilde uygulayabilecek kadar büyük olmalıdır. Bu çalışmada gözlem sayısı 120 olarak alınacaktır, diğer bir ifadeyle, asimetrik nedensellik analizi 120 günden oluşan alt-örneklere uygulanacaktır.

Zamanla değişen asimetrik nedensellik testinin genel işleyişi şu biçimde ifade edilebilir: Öncelikle birinci gözlemden 120. gözleme kadar olan aralık için Hatemi-J (2012) nedensellik testi uygulanır. İkinci aşamada; ilk gözlem atılıp, ikinci gözlem ile (120+1). gözlem aralığına bu test uygulanır ve test her yeni aşamada ilk gözlem atılıp, son gözleme bir yeni gözlem ekleme suretiyle veri aralığında yer alan son gözlem kullanılana kadar devam ettirilir. Elde edilen bu test istatistiklerinin anlamlılığını sınamak için her gözlem aralığında elde edilen test istatistiği bootstrap kritik değeri ile normalleştirilir. Burada üzerinde durulması gereken nokta, sadece Wald test istatistiklerinin değil, aynı zamanda bootstrap kritik değerlerinin de zamana bağlı olarak değişmesidir. Dolayısıyla, her gözlem aralığında elde edilen test istatistiği, bu gözlem aralığında elde edilen \%10 bootstrap kritik 
değeri ile normalleştirilir. Elde edilen Wald test istatistiklerini yorumlamak amacıyla değerler grafiğe dökülür. Grafikte, "1" çizgisinin yukarısında yer alan değerler asimetrik Granger-nedenselliğin olmadığını gösteren temel hipotezin reddedilmesi gerektiğini göstermektedir. Çalışmada test istatistikleri pozitif ve negatif şoklar için elde edildiğinden 4 farklı grafik elde edilecektir.

\section{VERI VE UYGULAMA SONUÇLARI}

Çalışmada Borsa İstanbul'a ait 1990-2012 dönemi günlük işlem hacmi ve hisse senedi endeksi kapanış fiyatları kullanılmıştır. Veri seti TCMB Elektronik Veri Dağıtım Sistemi'nden elde edilmiştir. Toplam gözlem sayısı 5731'dir. Günlük veri kullanılmasının nedeni;
Copeland (1991) tarafından da belirtildiği gibi ekonometrik açıdan daha fazla bilgi kullanımını sağlamasının yanı sıra iktisadi açıdan bir ay veya bir haftada ortadan kaldırılamayacak olan etkisizliğin günlük verilerle ortadan kaldırılabilmesidir.

Çalışmada Dolado ve Lütkepohl (1996) önerisi izleneceği için serilerin durağanlık derecelerini belirlemek gerekli değildir. Gecikme uzunluğu Hatemi-J (2003) kriteriyle belirlenen VAR modele, ilave olarak 1 gecikme eklenmiştir. Uygun kritik değerleri elde edebilmek amacıyla 10000 bootstrap simülasyonu yapılmıştır. Karşılaştırma yapabilmek amacıyla öncelikle Hatemi-J (2012) nedensellik testi uygulanmıştır. Elde edilen test sonuçları Tablo 1'de gösterilmektedir.

Tablo 1: Asimetrik Nedensellik Testi Sonuçları

\begin{tabular}{|c|c|c|c|c|c|c|}
\hline \multirow{2}{*}{ Model } & \multirow{2}{*}{ Temel Hipotez } & \multirow{2}{*}{ Test İstatistiği } & \multicolumn{2}{|c|}{ Kritik Değerler } & \multirow[b]{2}{*}{$5 \%$} & \multirow[b]{2}{*}{$10 \%$} \\
\hline & & & $\mathrm{k}$ & $1 \%$ & & \\
\hline Fiyat-Hacim & +7 & 1.543 & 4 & 13.403 & 9.522 & 7.709 \\
\hline & -7 & 3.762 & 3 & 11.241 & 7.83 & 6.275 \\
\hline Hacim-Fiyat & +7 & $84.116^{*}$ & 4 & 13.225 & 9.474 & 7.868 \\
\hline & -7 & $56.541^{*}$ & 3 & 12.111 & 7.756 & 6.279 \\
\hline
\end{tabular}

(Not: k, VAR modelin uygun gecikme uzunluğunu, * ise \%1 seviyesinde anlamlilığı göstermektedir.

Tablo 1'de görüleceği üzere, sadece işlem hacmindeki pozitif ve negatif şoklardan, sırasıyla fiyatlardaki pozitif ve negatif şoklara doğru nedensellik ilişkisi bulunmuştur. Sonuç olarak, asimetrik nedensellik analizi, işlem hacmindeki şoklardan hisse senedi fiyatlarındaki şoklara doğru tek yönlü bir ilişki olduğunu göstermektedir. Bununla birlikte, Tablo 1'de elde edilen sonuçlar tüm örnek periyodu dikkate alınarak elde edilmiştir. Bu sonuçların istikrarlı olup olmadığını sınamak amacıyla gerçekleştirilen zamanla değişen asimetrik nedensellik testinin sonuçları Şekil 1(a)-(d)'de gösterilmektedir?.

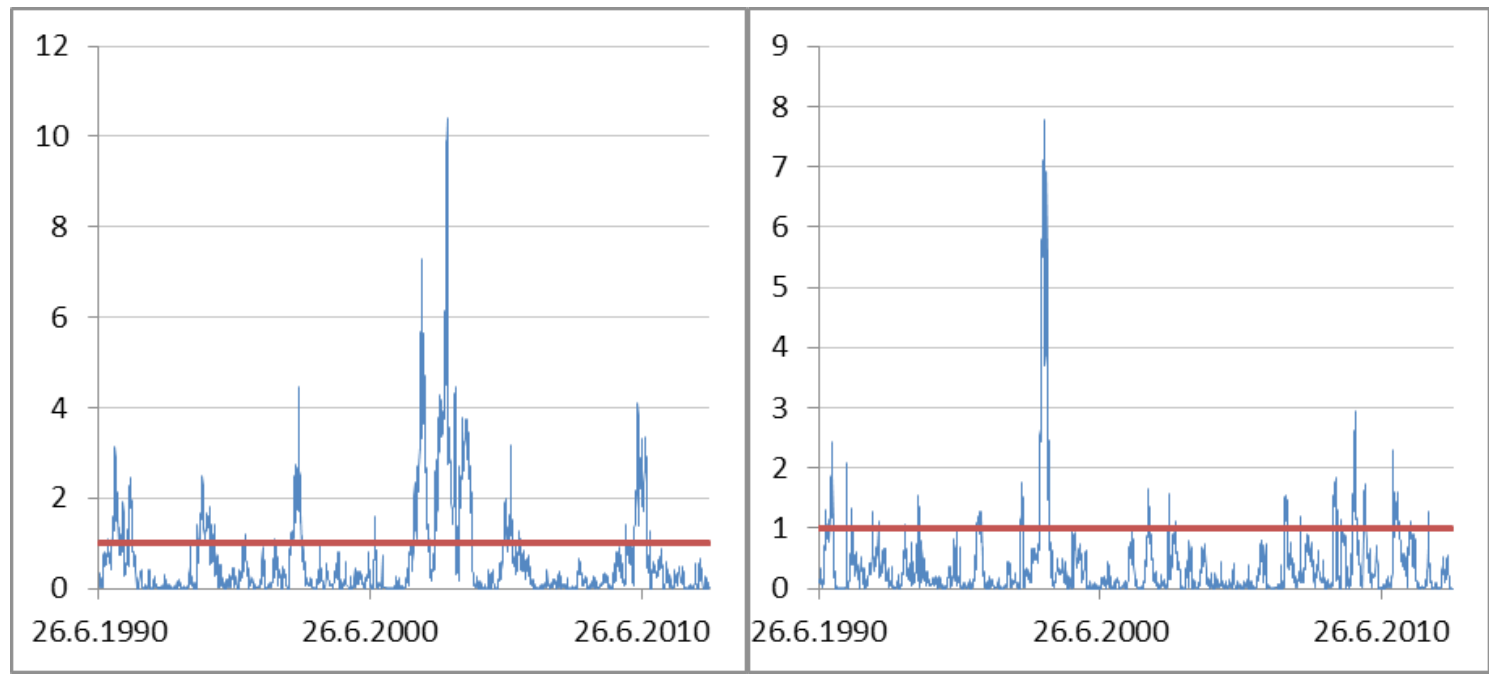

(a) Fiyat-Hacim İlişkisi (Pozitif Şoklar)

(b) Fiyat-Hacim İlişkisi (Negatif Şoklar) 


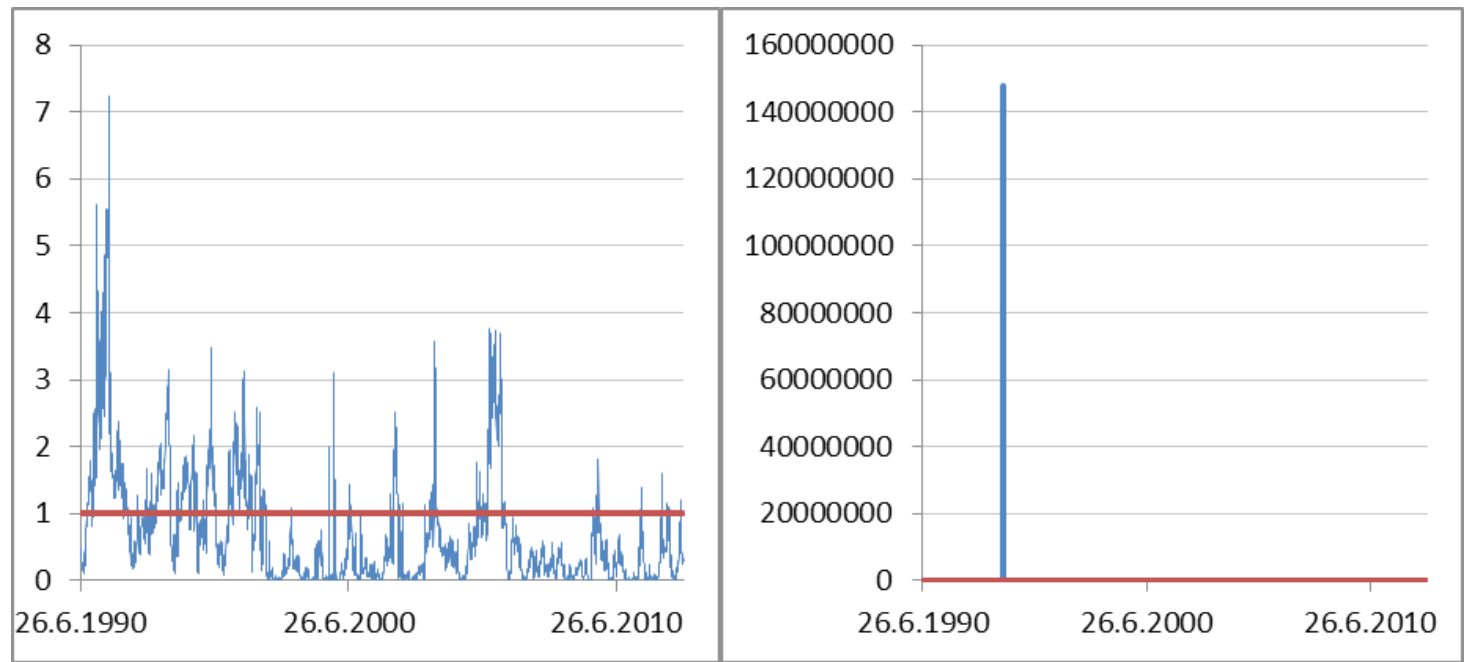

(c) Hacim-Fiyat Ilişkisi (Pozitif Şoklar)

(d) Hacim-Fiyat İlişkisi (Negatif Şoklar)

Şekil 1: Zamanla Değişen Asimetrik Nedensellik Testi Sonuçları

Tablo 1 fiyatlardaki pozitif şoklardan işlem hacmindeki pozitif şoklara ve yine aynı yönlü negatif şoklara doğru bir nedensellik ilişkisi olmadığını göstermektedir. Şekil 1 (a) ve Şekil 1(b) ise zaman aralığının önemli bir kısmı için bu sonucu doğrulamakla birlikte, pozitif şoklar için yurt içinde ve yurtdışında finansal çalkantıların $(1994,1997,2008)$ yaşandığı dönemler ile siyasal değişimlerin olduğu dönemlerde (2002, 2003) iki değişken arasında nedensellik ilişkisinin ortaya çıktığını göstermektedir. Negatif şoklar açısından 1998 Rusya krizinin iki değişken arasındaki ilişkiyi etkilediği düşünülebilir. Kriz dönemlerinde hisse senedi fiyatları ile işlem hacmi arasındaki pozitif ilişki, piyasa aktörlerinin bu tür dönemlerde benzer davranışlarda bulunduğunu göstermektedir. Ayrıca Tablo.1 işlem hacmindeki şoklardan fiyatlardaki şoklara doğru gerek pozitif gerekse de negatif şoklar açısından nedensellik ilişkisi olduğunu göstermektedir. Şekil 1 (c) ve 1 (d) incelendiğinde ise pozitif şoklar arasında sık ve uzun dönem boyunca gerçekleşen nedensellik ilişkisi söz konusuyken, negatif şoklar arasındaki nedensellik ilişkisinin tek bir dönem için geçerli olduğu görülmektedir. Negatif şoklardan elde edilen test istatistik değerinin küçük bir dönem için görece büyük olması da nedenselliğin geçici olduğunun diğer bir işaretidir. İşlem hacminden fiyatlara doğru olan pozitif şoklardaki nedenselliğin ise fiyatlardan işlem hacmine doğru olan ilişkiye benzer olarak, finansal çalkantıların ve siyasal gelişmelerin olduğu dönemlerde ortaya çıktığı görülmektedir.

\section{SONUÇ}

Bu çalışma, Türk sermaye piyasasında hisse senedi hisse senedi endeksi kapanış fiyatları ile işlem hacmi arasındaki nedensellik ilişkisini araştırmaktadır. Bu ilişkinin zamanla değişebileceği ve ilgili değişkenlerde meydana gelen negatif ve pozitif şoklara verilen tepkilerin farklı olabileceği dikkate alınarak gerçekleştirilen analiz sonuçları, nedensellik ilişkisinin zaman içerisinde değiştiğini, diğer bir ifadeyle istikrarlı olmadığını, ayrıca farklı şoklar için ilişkinin sıklığının ve kalıcılığının da farklılaştığını göstermektedir. Nedensellik ilişkisi pozitif şoklar için her iki yönde de ortaya çıkmaktadır. Negatif şoklar için ise işlem hacminden fiyatlara doğru sadece kısa bir dönem gözlenirken, fiyatlardan işlem hacmine doğru ise sıklığı az ve kısa dönemli bir nedensellik söz konusu olmaktadır. Bu sonuçlar, işlem hacmi ile hisse senedi fiyatları arasındaki ilişkinin pozitif şoklar için belirgin biçimde iki yönlü olduğunu göstermekte ve dolayısıyla Gürültülü İ̧lem Yaklaşımı́nın çıkarsamalarının geçerliliğini ifade etmektedir. Bu bağlamda, Türkiye hisse senedi piyasasında, yatırımcıların iktisadi temellere dayanmayan işlemleri nedeniyle fiyatların kısa dönemde denge patikasında seyretmediği ve piyasada yapılan işlemlerin geçmiş dönem fiyat hareketlerinden etkilendiği belirtilebilir. 


\section{SON NOTLAR}

${ }^{1}$ Bu tür çalışmaların bir özeti için: Karpoff (1987). Granger ve Morganstern (1963) ile Godfrey vd. (1964) hisse senedi getirileri ile işlem hacmi arasında ilişki olmadığını ileri sürmektedir.

${ }^{2}$ Hisse senedi piyasalarına ilişkin bir özdeyiş: "fiyatları hareket ettiren işlem hacmidir" biçimindedir (Osborne, 1967: 327). Bu özdeyiş finansal ekonomi literatüründe hisse senedi getirileri ile işlem hacmi arasındaki ilişkiye yönelik yoğun ilginin anlaşılır kılmaktadır.

3 Özellikle gelişmekte olan ülkelere ilişkin doğrusal teknikleri özetleyen bir literatür taraması için: Bkz. Darwish (2012).

${ }^{4}$ Ekonometrik metodolojinin yazımı için Hatemi-J (2012)'nin çalışması takip edilmiştir.
${ }^{5}$ Testin ișleyișini gösterebilmek amacıyla sadece pozitif şoklar arasındaki nedensellik ilişkisi üzerinde durulmuştur.

${ }^{6}$ Örneğin, Lean ve Tang (2010) ve Arslantürk vd. (2011) turizm gelirleri ile iktisadi büyüme arasındaki ilişkiyi test etmek amacıyla zamana bağlı değişen nedensellik analizinden faydalanmışlardır.

${ }^{7}$ Her alt örnek için hesaplanmış olan test istatistikleri, bootstrap kritik değerleri ve HJC kriteriyle belirlenmiş olan uygun gecikme uzunlukları yazarlardan temin edilebilir. Hatemi-J tarafından asimetrik nedensellik testini uygulamak için yazılmış olan Gauss program kodu, zamanla değişen asimetrik testini uygulamak için yazarlar tarafından geliştirilmiştir.

\section{KAYNAKLAR}

Al-Deehani, T.M. (2007) "Modeling Asymmetry in the Price-Volume Relation: Evidence from Nine Stock Markets" Investment Management and Financial Innovations, 4(4):8-15.

Andersen, T. (1996) "Return Volatility and Trading Volume:An Information Flow Interpretation of Stochastic Volatility" Journal of Finance, 51(1):169-204.

Arslantürk, Y., Balcılar, M. ve Özdemir, Z.A. (2011) "Time-Varying Linkages between Tourism Receipts and Economic Growth in a Small Open Economy" Economic Modelling, 28(1-2):664-671.

Assogbavi, T. ve Osagie, J. (2006) "Equity Valuation Process and Price-Volume Relationship on Emerging Stock Markets" International Business and Economics Research Journal, 5:7-18.

Başçı, E., Özyıldırım, S. ve Aydoğan, K. (1996) "A Note on Price-Volume Dynamics in an Emerging Stock Market" Journal of Banking and Finance, 20:389-400.

Bayrakdaroğlu, A. ve Nazlığlu, Ş. (2009) "Hisse Senedi Fiyat-Hacim İlişkisi: İMKB'de İşlem Gören Bankalar için Doğrusal ve Doğrusal Olmayan Granger Nedensellik Analizi" İktisat, İsletme ve Finans Dergisi, 24(277):85-109.

Blume, L., Easley, D., ve O’Hara, M. (1994) "Market Statistics and Technical Analysis: The Role of Volume" Journal of Finance, 49:153-181.

Brooks, C. ve Hinich, M. J. (1998) "Episodic Nonstationarity in Exchange Rates" Applied Economics Letters, 5(11):719-722.

Campbell, J., Grossman, S. ve Wang, J. (1993) "Trading Volume and Serial Correlation in Stock Returns" Quarterly Journal of Economics, 108:905-939.
Chen, G., Firth, M., ve Rui, O.M. (2001) "The Dynamic Relation between Stock Returns, Trading Volume, and Volatility" Financial Review, 38:153-174.

Chuang, C.C., Kuan, C.M. ve Lin, H.Y. (2009) "Causality in Quantiles and Dynamic Stock ReturnVolume Relations" Journal of Banking and Finance, 33:1351-60.

Clark, P. (1973) "A Subordinated Stochastic Process Model with Finite Variance for Speculative Prices" Econometrica, 41:135-155.

Copeland, L. (1991) "Cointegration Tests with Daily Data" Oxford Bulletin of Economics and Statistics, 53(2):185-198.

Copeland, T.E. (1976) "A Model of Asset Trading Under the Assumption of Sequential Information Arrival" Journal of Finance, 31:1149-1168.

Çukur, S., Gümrah, Ü. ve Gümrah, M.Ü. (2012) "İstanbul Menkul Kıymetler Borsasında Hisse Senedi Getirileri ve İşlem Hacmi İlişkisi” Niğge Üniversitesi İIBFF Dergisi, 5(1):20-35

Darwish, M. (2012) “Testing the Contemporaneous and Causal Relationship between Trading

Volume and Return in the Palestine Exchange" International Journalof Economics and Finance, 4(4):182-192.

De Long, J., Shleifer, A., Summers, L., ve Waldmann, R. (1990) "Positive Feedback, Investment Strategies, and Destabilizing Rational Speculation" Journalof Finance, 45:379-395.

Dolado, J.J. ve Lütkepohl, H. (1996) "Making Wald Tests Work for Cointegrated VAR Systems" Econometric Theory, 15(4):369-386. 
Elmas, B., ve Temurlenk, M.S. (2009) "Hisse Senedi Fiyatı-İlem Hacmi Arasındaki Granger Nedensellik: İMKB'de Hisse Bazlı Bir Analiz" IMKB Dergisi, 11(43):1-15

Epps, T. ve Epps, M.L. (1976) "The Stochastic Dependence of Security Price Changes and Transaction Volumes: Implication for the Mixture-of-Distributions Hypothesis" Econometrica, 44:305-21.

Fama, E.F. (1970) "Efficient Capital Markets: A Review of Theory and Empirical Work" Journal of Finance, 25:383- 417.

Gerlach, R., Chen, C.W.S., Lin, D.S.Y. ve Huang, M.H. (2006) "Asymmetric Responses of International Stock Markets to Trading Volume" Physica A: Statistical Mechanics and its Applications, 360(2): 422-444.

Godfrey, M.D., Granger, C.W.J. ve Morgenstern, O. (1964) "The Random-Walk Hypothesis of Stock Market Behavior" Kyklos, 17(1):1-30.

Granger, C.W.J. ve Morgenstern, O. (1963) "Spectral Analysis of New York Stock Market Prices” Kyklos, 16(1):1-27.

Granger, C.W. J. (1969) "Investigating Causal Relations by Econometric Models and Cross Spectral Methods" Econometrica, 37:424-438.

Granger, C.W.J. ve Yoon, G. (2002) "Hidden Cointegration" Department of Economics Working Paper University of California, No:2002-02.

Gökçe, A. (2002) “IMKB'de Fiyat-Hacim İlişkisi: Granger Nedensellik Testi” İktisat, İsletme ve Finans Dergisi, 17(201):44-47.

Gündüz, L. ve Hatemi-J, A. (2005) "Stock Price and Volume Relation in Emerging Markets" Emerging Markets Finance and Trade, 41:29-44.

Hacker, R.S. ve Hatemi-J, A. (2006) "Tests for Causality between Integrated Variables Using Asymptotic and Bootstrap Distributions: Theory and Application" Applied Economics, 38(13):1489-1500.

Hacker, R.S. ve Hatemi-J, A. (2008) "Optimal Lag Length Choice in the Stable and Unstable VAR Models Under Situations of Homoscedasticity and Heteroscedasticity" Journal of Applied Statistics, 35(6):601-615.

Hatemi-J, A. (2003) "A New Method to Choose Optimal Lag Order in Stable and Unstable VAR Models" Applied Economics Letters, 10(3):135-137.

Hatemi-J, A. (2012) "Asymmetric Causality Tests with an Application" Empirical Economics, 43(1):447-456.

Hiemstra, C. ve Jones, J.D. (1994) "Testing for Linear and Nonlinear Granger Causality in Stock Price-Volume Relation" Journal of Finance, 49:1639-1664
Hsiao, C. (1981) "Autoregressive Modelling and Money-Income Causality Detection” Journal of Monetary Economics, 7(1): 85-106

Jennings, R., Starks, L. ve Fellingham, J. (1981) “An Equilibrium Model of Asset Trading with Sequential Information Arrival" Journal of Finance, 36:143-161.

Kamath, R. (2007) "Investigating Causal Relations between Price Changes and Trading Volume Changes in the Turkish Stock Market" American Society of Business and Behavioural Science, 3(1):30-40.

Karpoff, J. (1987) "The Relation between Price Changes and Trading Volume: A Survey" Journal of Financial and Quantitative Analysis, 22:109-125.

Kayalıdere, K. ve Aktaş, H. (2009) "IMKB'de FiyatHacim İlişkisi - Asimetrik Etkileşim” Yönetim ve Ekonomi, 16(2):49-62

Lakonishok J. ve Smidth, S. (1989) "Past Prices Changes and Current Trading Volume" Journal of Portfolio Management, 15:18-24.

Lean H.H. ve Tang, C.H. (2010) "Is the TourismLed Growth Hypothesis Stable for Malaysia? A Note" International Journal of Tourism Research, 12:375-378.

Lee, C.F. ve Rui, O.M. (2000) “Does Trading Volume Contain Information to Predict Stock Retums? Evidence from China's Stock Markets" Review of Quantitative Finance and Accounting, 14:341-360.

Lee, B.S. ve Rui, O. (2002) "The Dynamic Relationship between Stock Return and Trading Volume: Domestic and Cross-country Evidence" Journal of Banking and Finance, 26:51-78.

Lin, H.Y. (2013) "Dynamic Volume-Return Relation: Evidence from Emerging Asian Markets" Bulletin of Economic Research, 65(2):178-193

Lütkepohl, H. (1985) "Comparison of Criteria for Estimating the Order of a Vector Autoregressive Process" Journal of Time Series Analysis, 6:35-52.

Ngo, T.N. ve Surendranath, J. (2008) "International Evidence on the Relationship between Trading Volume and Serial Correlation in Stock Returns" Global Journal of Finance and Banking Issues, 2(2):1-13.

Osborne, M.F.M. (1967) "Some quantitative tests for stock price generating models and trading folklore" Journal of the American Statistical Association, 62(318):321-340.

Pisedtasalasai, A. ve Gunasekarage, A. (2007) "Causal and Dynamic Relationships among Stock Returns, Return Volatility and Trading Volume: Evidence from Emerging Markets in South-East Asia" Asia-Pacific Financial Markets, 14:277-97. 
Silvapulle, P. ve Choi, J. (1999) "Testing for Linear and Nonlinear Granger Causality in the Stock PriceVolume Relation:Korean Evidence" Quarterly Review of Economics and Finance, 39:59-76.

Sims, C.A. (1972) "Money, Income, and Causality" American Economic Review, 62(4): 540-552

Tauchen, G. ve Pitts, M. (1983) "The Price Variability-Volume Relationship on Speculative Markets" Econometrica, 51:485-505.

Tang, C.F. (2008) “Wagner's Law Versus Keynesian Hypothesis: New Evidence from Recursive RegressionBased Causality Approaches" ICFAI Journal of Public Finance, 6(4): 29-38.

Toda, H.Y. ve Yamamoto, T. (1995) "Statistical Inference in Vector Autoregressions with Possibly Integrated Processes" Journal of Econometrics, 66(12):225-250.

Umutlu, G. (2008) “İşlem Hacmi ve Fiyat Değişimleri Arasındaki Nedensellik ve Dinamik İlişkiler: İMKB'de Bir Ampirik İnceleme" Gazi Üniversitesi İktisadi ve İdari Bilimler Fakültesi Dergisi, 10(1):231-246.

Yörük, N., Erdem, C. ve Erdem, M.S. (2006) "Testing for Linear and Nonlinear Granger Causality in the Stock Price-Volume Relation: Turkish Banking Firms' Evidence" Applied Financial Economics Letters, 2:165-171. 